\title{
OCCUPATIONAL RISK AND HEALTH STATUS OF WORKERS IN THE PRODUCTION OF HEAT
}

\author{
Tanja P. Kuneva, \\ Zlatka B. Stoyneva, \\ Daniela G. Medjidieva, \\ Diana B. Apostolova, \\ Shiboy N. Kuzmov, \\ Gergina N. Oncheva, \\ Reny T. Toncheva, \\ Vladimira V. Boyadzhieva, \\ Kristina V. Bozhinova
}

Clinic of Occupational Diseases, University Hospital "St. Iv. Rilski", Sofia

\section{Corresponding Author.}

Tanja P. Kuneva

University Hospital "St. Ivan Rilsky”

15 Acad. Ivan Geshov str.

Sofia, 1431

Bulgaria

e-mail:tanjakuneva@abv.bg

Received: October 30, 2014

Revision received: December 02, 2014

Accepted: December 19, 2014

\section{Summary}

The health status of 1515 workers employed in heat production was investigated. The subjects studied were divided in four groups according to occupation and occupational risk factors: vibration, noise, dust, metal aerosols, overloading of the musculoskeletal and peripheral nervous system, and organic solvents. The control group included 152 administrative staff members. High prevalence of socially significant diseases cardiovascular, endocrine and metabolic was detected in all the groups surveyed. The frequency of diseases of the cardiovascular system and the respiratory system was 2.7 times higher than that in the control group. Statistically reliable higher prevalence of lung diseases in the studied risk groups was found, especially in the group of welders and chemists: $45.3 \%$ и $17.4 \%$ respectively, as compared to $4.3 \%$ in the controls. These finding corresponded to the occupational risk. The following occupation diseases were diagnosed: pneumoconiosis in $26.6 \%$ and toxic pneumofibrosis in $5.1 \%$ of electric welders. As regards the group of chemists, toxic pneumofibrosis was found in $6.5 \%$. toxic effects of irritants - in $6.5 \%$, and chronic intoxication with organic radicals - in $0.7 \%$ of them. Occupational auditory neuritis was diagnosed in $1 \%$ of the turbine operators and crane operators. The relative share of workers with peripheral nervous system pathology (radiculopathies, polyneuropathies, distal sympathetic neuropathy, mononeuropathy) was reliably higher than that in the control group, and the frequency increased among the workers with more than ten years of service and older than 40 .

Key words: occupational risk, occupational diseases, toxic pneumofibrosis, hepatitis

\section{Introduction}

According to data from the National Social Security Institute of Bulgaria, the numbers of cases of occupational diseases are very few and so rare that they seem accidental.

Socioeconomic conditions discourage doctors working in general practice and in hospitals submit timely information about suspected occupational diseases. This impedes the resolution of potential cases and distorts the information concerning the true rates of occupational diseases. Presently, regular 
check ups are one of the reliable sources of information regarding the health status of employees. The check ups for employees working exposed to occupational hazards are regulated by Ordinance No. 3 of the Ministry of Health - State Gazette, No. 16/1987 (amended and supplemented, No. 102/1994). The objectives of these periodic medical examinations include early diagnosis of both socially relevant and occupational diseases, monitoring the dynamic changes in chronic diseases, assessment of capacity for work, referral for diagnosis in hospital conditions, transfer to other jobs and/or expertise assessment.

Working in an thermo-electric power-station involves exposure to dust, gases, metal aerosols, solvents, vibration, noise, overstrain of the musculoskeletal system, adverse microclimate etc., all of which associate with a number of diseases related to work and occupation $[1,2]$.

The study aimed to analyse the health status of workers at a thermo-electric power station in Sofia, detect early signs of occupational diseases and design a program to eliminate or reduce the impact of adverse risk factors on the working environment.

\section{Materials and Methods}

We examined and investigated 1515 employees of the thermo-electric power-station in Sofia. The control group included 152 members of administrative staff, employed by Siemens. The study group and the control group were matched by age, sex and length of service.

The workers we investigated were divided into four risk groups according to concrete occupational hazards: dust, gases, metal aerosols, organic solvents, vibration, noise, overload of the musculoskeletal system, adverse microclimate, etc. The distribution of the subjects included in the study by occupation, risk factors, medical examinations and investigations is presented on Table 1.

\section{Statistical methods}

Data analyses were made using EXCEL and SPSS software packages. To summarize and classify the data, we used methods of descriptive statistics, parametric and non-parametric analyses. Comparisons were made by the tcriterion of Student. The $\chi^{2}$ method was applied to process the independent data in $2 \times 2$ contingency tables. P-values $<0.05$ were regarded as statistically significant.

Table 1. Distribution by occupational groups and completed medical examinations

\begin{tabular}{|c|c|c|c|c|c|}
\hline No. & Number & $\begin{array}{c}\text { Working positions } \\
\text { (type of activity) }\end{array}$ & Risk factors & $\begin{array}{c}\text { Medical } \\
\text { examinations }\end{array}$ & Tests \\
\hline $\mathrm{I}$ & 64 & electric welders & $\begin{array}{l}\text { gases, vapors, } \\
\text { fumes, metal } \\
\text { aerosols }\end{array}$ & $\begin{array}{l}\text { pulmonologist } \\
\text { toxicologist } \\
\text { ENT } \\
\text { neurologist }\end{array}$ & $\begin{array}{l}\text { ECG, } \\
\text { Pulmonary function testing (PFT) } \\
\text { Lung X-ray }\end{array}$ \\
\hline II & 138 & chemists & $\begin{array}{l}\text { acids, alkalis } \\
\text { org. solvents } \\
\text { (benzene, gasoline, } \\
\text { chloroform, oils) }\end{array}$ & $\begin{array}{l}\text { toxicologist } \\
\text { neurologist } \\
\text { ENT }\end{array}$ & $\begin{array}{l}\text { ECG, PFT, lung X-ray } \\
\text { complete blood count (CBC), differential } \\
\text { blood count (DBC), erythrocyte } \\
\text { sedimentation rate (ESR) } \\
\text { ASAT, ALAT, GGTP, cholesterol and 3- } \\
\text { glycerides, threshold and suprathreshold } \\
\text { audiometry }\end{array}$ \\
\hline III & 98 & $\begin{array}{l}\text { crane operators } \\
\text { excavator } \\
\text { operators } \\
\text { front loader } \\
\text { operators } \\
\text { drivers } \\
\end{array}$ & $\begin{array}{l}\text { excessive vibration } \\
\text { levels, noise }>85 \\
\mathrm{~dB}\end{array}$ & $\begin{array}{l}\text { therapeutist } \\
\text { ENT } \\
\text { neurologist }\end{array}$ & $\begin{array}{l}\text { ECG, cold test } \\
\text { alternating dynamometrics } \\
\text { capillaroscopy, vibration perception } \\
\text { threshold, threshold and suprathreshold } \\
\text { audiometry }\end{array}$ \\
\hline IV & 1215 & $\begin{array}{l}\text { operators and } \\
\text { fitters of steam } \\
\text { turbines }\end{array}$ & $\begin{array}{l}\text { Noise } 85-102 \mathrm{~dB}, \\
\text { physical load, } \\
\text { adverse } \\
\text { microclimate }\end{array}$ & $\begin{array}{l}\text { therapeutist } \\
\text { ENT } \\
\text { neurologist }\end{array}$ & $\begin{array}{l}\text { ECG } \\
\text { threshold and suprathreshold audiometry } \\
\text { alternating dynamometrics }\end{array}$ \\
\hline
\end{tabular}


Table 2. Distribution of individuals by sex, age and length of service

\begin{tabular}{llllllll}
\hline \multirow{2}{*}{ Group } & Total number & \multicolumn{2}{c}{ Sex } & & Age & \multicolumn{2}{c}{$\begin{array}{c}\text { Specialized length of } \\
\text { service }\end{array}$} \\
\cline { 3 - 8 } & & males & females & $\begin{array}{c}\text { Up to } 40 \\
\text { years }\end{array}$ & over 40 years $\begin{array}{c}\text { Up to 10 } \\
\text { years }\end{array}$ & $\begin{array}{c}\text { over 10 } \\
\text { years }\end{array}$ \\
\hline I & 64 & 64 & - & 15 & 49 & 22 & 42 \\
\hline II & 138 & 57 & 81 & 19 & 119 & 19 & 119 \\
\hline III & 98 & 93 & 5 & 15 & 83 & 21 & 77 \\
\hline IV & 1215 & 902 & 313 & 347 & 868 & 402 & 813 \\
\hline Total number & 1515 & 1116 & 399 & 396 & 1119 & 464 & 1051 \\
\hline$\%$ & 100 & 73.7 & 26.3 & 26.1 & 73.9 & 30.6 & 69.4 \\
\hline
\end{tabular}

\section{Results}

Table 2 presents data about sex, age and length of service of the subjects studied. The males outnumbered the females, accounting for $73.7 \%$ versus $26.3 \%$ of the subjects. Those aged over 40 were $74 \%$, and $69.4 \%$ had specialized service over ten years. In the group investigated, length of service varied from a few months to 30 years.

Figure 1 presents the results from medical examinations of both the study and the control group, performed by specialists in internal diseases and the conditions identified by systems. In both groups, prevalence of socially relevant diseases (cardiovascular, endocrine and metabolic) prevailed. It should be noted that the incidence of cardiovascular and respiratory diseases was 2.7 times higher in the study group, as compared to the controls. We did not find statistically reliable differences between the risk groups and the control group regarding the incidence of all other diseases. (Figure 1)

Of the internal diseases diagnosed, those of the cardiovascular system ranked first $-37.4 \%$, represented mainly by arterial hypertension $(35.5 \%)$ and ischaemic heart disease $(1.9 \%)$. Pronounced hypertension and mild hypertension was found in $28 \%$ and $7.5 \%$, respectively. The majority of the workers with cardiovascular diseases were men aged over 40 , obese and with a family history, with poorly controlled blood pressure and not abiding to any dietary regimen. Regarding the incidence of cardiovascular diseases, there were no statistically reliable differences between the four risk groups.

The pattern of respiratory diseases in the risk groups was different in each group and correlated with the occupational risks (Figure 2). In groups I and II, the incidence rate of respiratory diseases was significantly higher $(45.3 \%$ and $17.4 \%$, respectively) than that in the control group $(4.3 \%)$, and higher than the rates in groups III and $\operatorname{IV}(8.2 \%$ и $6.9 \%$, respectively).

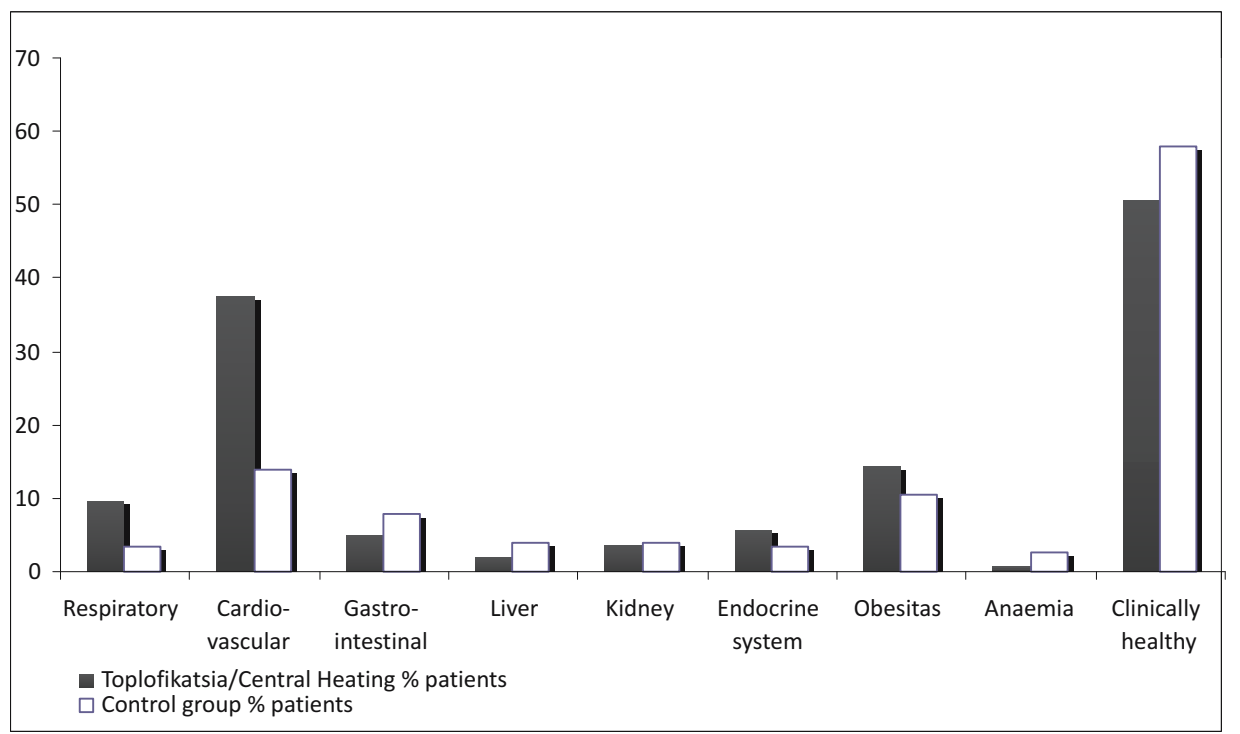

Figure 1. Registered diseases in study groups and controls (\%) 


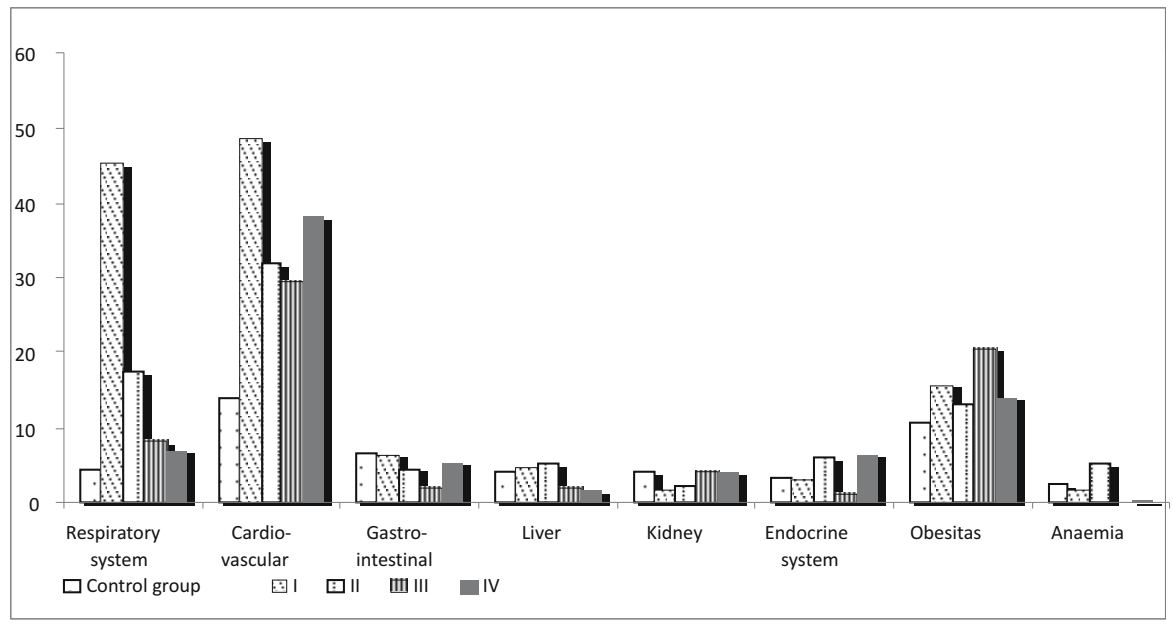

Figure 2. Registered diseases by risk groups and systems

The lung diseases registered in $45.3 \%$ of the subjects in the group of welders were mainly presented by pneumofibrosis and chronic bronchitis. Radiographic evidence of the pneumofibrosis was found in $32.7 \%$ of the subjects. Initial pulmonary fibrosis was diagnosed in 4 workers with shorter length of service and most likely it was post-pneumonic fibrosis. In 17 subjects (26.6\%) occupationinduced genesis of the fibrosis was considered, i.e. - pneumoconiosis in electric welders due to prolonged exposure (over 10 years) to welding gases in the absence of other fibrogenic factors. Clinical evidence of chronic bronchitis with mixed ethiopatogenesis was found in $12.5 \%$, as a result of working with metal aerosols and systematic smoking.

In the group of chemists, the highest prevalence was that of cardiovascular diseases $(32 \%)$, followed by respiratory diseases $(17.4 \%)$. Toxic pneumofibrosis was discussed in $5.1 \%$ of them. In $5.8 \%$, mixed etiology of pneumofibrosis was revealed as a result of former pneumonia and irritative action of acids and bases. Clinical and laboratory evidences of chronic bronchitis were present in $5.8 \%$, of acute bronchitis - in $0.7 \%$ and asthma - in $0.7 \%$. Although it was supposed that the causes of these conditions were related to living conditions and infections, the irritants present in the working environment were suspected as contributing to worsening and protraction of the diseases. Toxic effects of irritants in chronic pharyngolaryngitis, anaemia and bronchitis were diagnosed in $6.5 \%$ of the studied workers.

We detected liver disorders in $5.1 \%$ of the chemists. In most of the cases, they were related to steatosis, corresponding with concomitant obesity and dyslipidemia. Chronic hepatitis was diagnosed in chemists: one with ethylic, the other with toxic genesis due to chronic intoxication with organic solvents manifested by the following syndrome complex: toxic anaemia, chronic pharyngitis and toxic hepatitis.

In risk groups III and IV cardiovascular (29.6\% and $38.1 \%$, respectively) and metabolic diseases (20.4\% and $13.9 \%$, respectively) also dominated.

Pathological disorders of the nervous (NS) and musculoskeletal systems (MSS) were registered in $45.8 \%$ (Figure 3 ). Lesions of spinal roots in the lumbar and cervical spine prevailed $34.06 \%$ (lumbar radiculopathies in 19\% and 15\% cervical radiculopathies, respectively). These were mostly found in electric welders (Group I (39.06 and among the boiler and turbine equipment operators and fitters (Group IV, $39.01 \%$ ), followed by crane, excavator and front loader operators (Group III, 29.49\%) and corresponded to the risk factors (Figure 4).

The lowest percentage of radiculopathies $(21.7 \%)$ was found in chemists (group II). In $2.2 \%$ of the examined workers distal autonomic neuropathy of the upper limbs with angiodystonic disorders was found, probably due to occupational exposure to vibration and overload.

Diseases involving the musculoskeletal system were diagnosed in $21.6 \%$ of the workers. Bone and joint degenerative changes were found in $10.8 \%$ of them, the highest prevalence being that of spondylosis and osteochondrosis $(9.31 \%)$, particularly in its lumbar part (8.2\%). Articular 


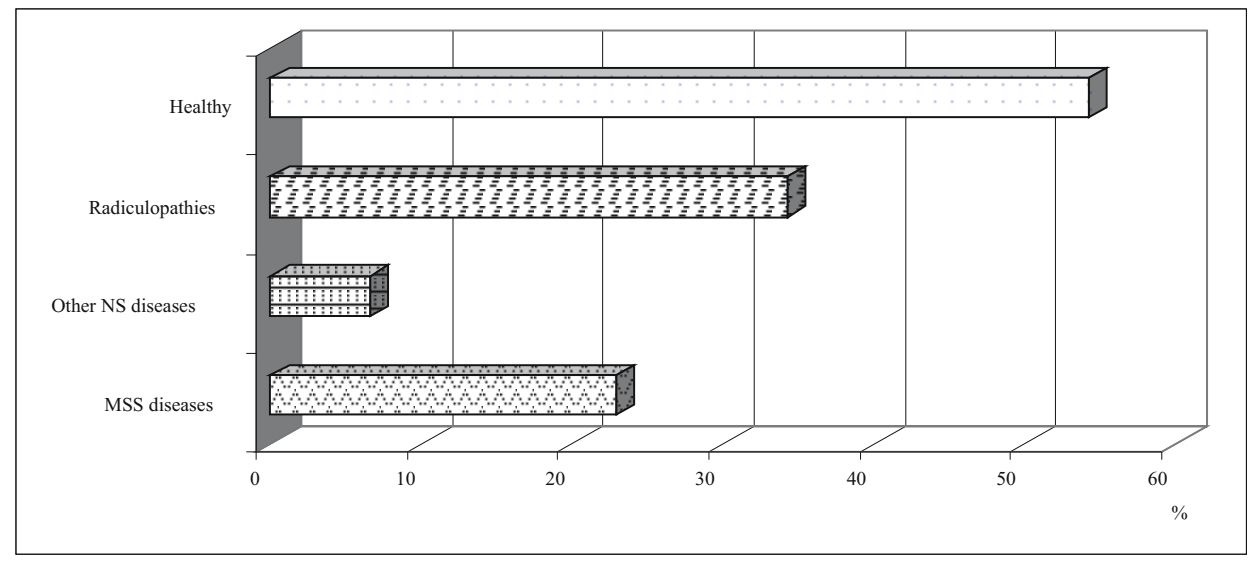

Figure 3. Prevalence of nervous and musculoskeletal system pathology

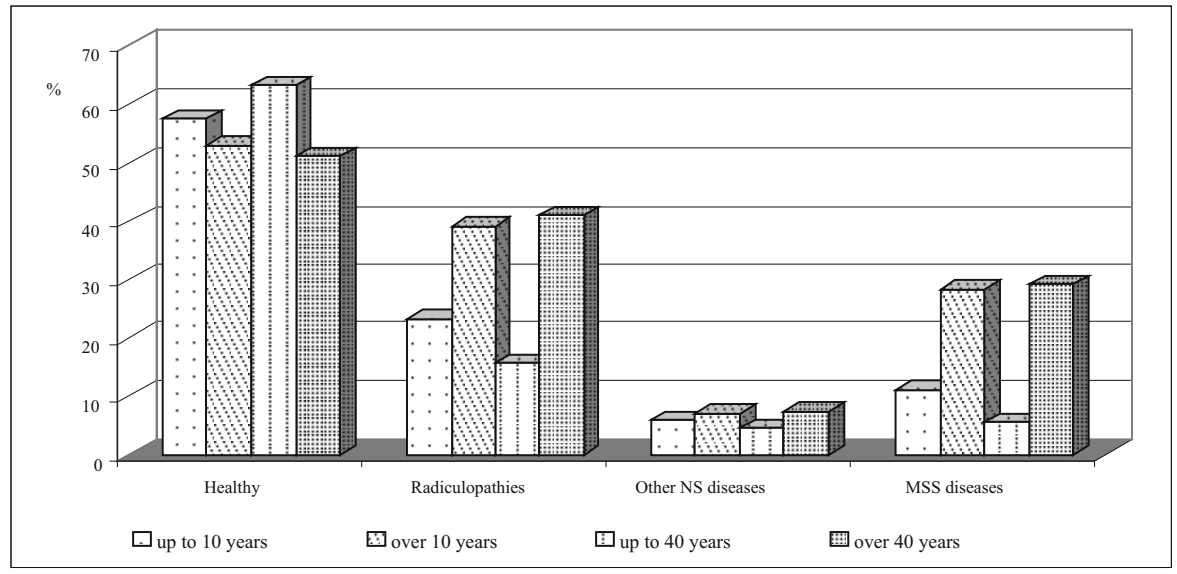

Figure 4. Prevalence of nervous and musculoskeletal systems pathology according to length of service and age

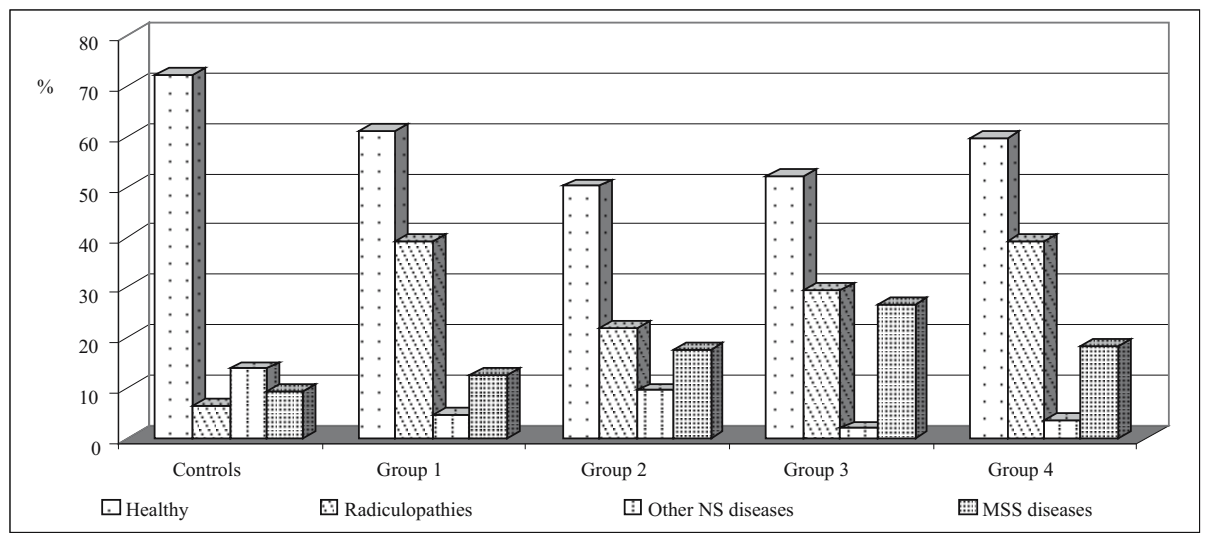

Figure 5. Prevalence of nervous and musculoskeletal systems pathology by groups

and periarticular diseases (humeroscapular periarthritis, radial and/or ulnar epicondylitis of the humerus, gonarthrosis, coxarthrosis, etc.) accounted for $6.7 \%$ of the degenerative changes.
The highest prevalence of musculoskeletal diseases was found in crane operators in Group III $(26.53 \%)$, followed by the operators of turbines in Group IV (18.44\%) and the chemists 
in Group II (17.39\%), and the lowest being among the electric welders in Group I (12.5\%) (Figure 4). The prevalence of nervous and musculoskeletal disorders was significantly higher in workers with length of specialized service with occupational risk factors over 10 years and aged over 40 (Figure 5).

Regarding ENT diseases, those affecting the auditory analyzer were prevalent. Among these, bilateral auditory neuritis ranked first (5\%), with prevalence of mild forms $(4.5 \%)$ and a relatively small share of the moderate and severe forms $(0.3 \%$ and $0.2 \%$, respectively). In $1 \%$ of the cases, a causal relationship was found, and hearing problems were diagnosed mostly in crane operators $(9.1 \%)$ and fitters $(7.1 \%)$.

\section{Discussion}

In the literature available there are no publications regarding the health status of workers in a thermo-electric power-station. It is well known that they are exposed to occupational hazards such as dust, gases, metal aerosols, solvents, vibration, noise, overstrain and physical static and dynamic overload of the musculoskeletal and peripheral nervous systems, adverse microclimate etc., which are associated with a number of occupational diseases [1-3].

The study analyses the health status of subjects employed in a station in Sofia. The majority of the subjects were found to be clinically healthy, although many of the disorders could be occupational or work-related. Socially significant diseases - cardiovascular diseases, endocrine and metabolic, were prevalent in both the study groups and the controls. Arterial hypertension and ischemic heart disease accounted for $35.5 \%$ and $1.9 \%$, respectively. Dyslipidemia, obesity, age, sex, presence of diabetes, unhealthy habits and family history have been proved to be contributing factors in arterial hypertension [4]. Undoubtedly, the excessive noise to which fitters, turbine operators and drivers are exposed, has an effect on cardiac function but noise itself does not cause hypertension.

Therefore, the hypertension registered could not be linked to occupational risk factors only: except for two of them, all the subjects with hypertension were over 40 years of age, with obesity and a family history. The pulmonary diseases (chronic bronchitis and pneumofibrosis), however, were etiologically associated with exposure to toxic gases and organic solvents.

Liubchenko and Vinnitskaia have reported that of the occupational diseases diagnosed in 323 welders, the most common was pneumoconiosis, followed by sensorineural deafness, chronic toxic dust bronchitis and chronic manganese intoxication $[5,6]$. In 17 welders $(26.6 \%)$ we established occupationrelated etiology of the fibrosis diagnosed pneumoconiosis due to over ten years of exposure mostly to gases in the absence of other risk factors associated with fibrosis. Toxic pneumofibrosis was found in $10 \%$, and toxic effects of irritants - in 5\% of them. Chronic intoxication with with organic solvents was found in $0.7 \%$ of the chemists. Clinical data of chronic bronchitis with mixed etiopathogenesis (exposure to metal aerosols and regular smoking) was found in $12.5 \%$. Toxic effects of irritants, resulting in chronic pharyngolaryngitis, anemia and bronchitis were established in $12.5 \%$ of the subjects investigated. Although factors for these conditions are mainly linked to living conditions, life-styles and infections, the presence of irritants in the working environment definitely contribute to more frequent exacerbations and longer periods of sickness.

It was concluded that welders diagnosed with pneumofibrosis were subject to prompt labour readjustment to avoid exposure to dust and irritants, in view of the irreversibility of the process and progression to chronic respiratory insufficiency.

Hepatotoxic and myelotoxic effects of organic solvents have long been known [7-9]. However, the steatosis diagnosed in the majority of the chemists was more likely due to obesity and dyslipidemia.

Noise and vibration have non-specific effects on many internal organs (ptosis of stomach, liver, kidneys, etc.) but in this study no such disorders were found in either of these two groups. Occupational auditory neuritis was detected in only $1 \%$ of crane operators and fitters.

The highest prevalence of peripheral nervous and musculoskeletal disorders was established in electric welders, excavator operators and crane operators. Reliably higher prevalence of cervical and/or lumbosacral radiculopathes was associated with service longer than 10 years and over 40. So their etiology was complex and mixed due to both occupational risk factors (vibration, static and dynamic overload and overstrain) and also to age-related vertebral 
degeneration (spondylosis) and/or intervertebral changes (disc herniation, osteochondrosis, sponylolisthesis) [10-12]. Therefore, most of the musculoskeletal and nervous changes are workrelated, and some of them are occupational, but should be further discussed.

\section{Conclusion}

Occupational risk for workers in a thermoelectric power-station involves the respiratory, nervous and musculoskeletal systems, the liver and the auditory analyser. Our findings suggest that strict monitoring of the health status is needed to provide early diagnosis and prevention of occupational and work-related diseases. Further investigation could help to better estimate the association between hazardous risks at the workplace and the diseases of workers exposed to different occupational risk factors.

\section{References}

1. Comar CL, Sagan LA. Health Effects of Energy Production and Conversion. Annual Review of Energy. 1976;1:581-600.

2. da Costa BR, Vieira ER. Risk factors for workrelated musculoskeletal disorders: A systematic review of recent longitudinal studies. Am J Ind Med. 2010;53(3):285-323.
3. Fritzsche AF. The Health Risks of Energy Production. Risk Analysis, 1989;9(4);565-77.

4. Elenkova A, Kadreva-Tarnovska. Arterial Hypertension. In: Krastev $\mathrm{Z}$ editor, Internal Medicine $2^{\text {nd }}$ ed. Sofia: Ivan Sapundzhiev EOOD; 2010.p. 136-148.

5. Liubchenko PN, Vinnitskaia TE. The structure of occupational morbidity in electric welders. Med $\mathrm{Tr}$ Prom Ekol. 2000;8:7-10. Russian.

6. Yu IJ, Song KS, Chang HK, Han JH, Chung YH, Han KT, et al. Recovery from manual metal arcstainless steel welding-fume exposure induced ling fibrosis in Sprague-Daawley rats. Toxicol Lett. 2003;143(3):247-59.

7. Petkova E. Occupational diseases of inorganic powders. Sofia; Investpres AD: 2005.

8. Apostolova D. Petrol. Benzene and homologues. In: Kostova V, Petkova V, editors. Occupational diseases. Sofia: Ral-kolobar; 2007. p. 72-8.

9. Petkova, V. Poisoning with organic solvents. . In: Kostova V, Petkova V, editors. Occupational diseases. Sofia: Ral-kolobar; 2007. p. 70-2.

10. Burström L, Nilsson T, Wahlström J. Whole-body vibration and the risk of low back pain and sciatica: a systematic review and meta-analysis. Int Arch Occup Environ Health. 2014. doi: 10.1007/s00420-014-0971.4.

11. Punnett L. Musculoskeletal disorders and occupational exposures: how should we judge the evidence concerning the causal association? Scand J Public Health. 2014;42(13 Suppl):49-58.

12. Bovenzi M. Criteria for case definitions for upper limb and lower back disorders caused by mechanical vibration. Med Lav. 2007;98(2):98110. 